\title{
Modelo de relaciones retóricas para la integración de la imagen y el texto
}

\section{A model of rhetorical relations for the integration of the image and the word}

\author{
Giorgio P. De Marchis \\ Profesor Contratado Doctor, Universidad Complutense de Madrid \\ Beatriz Hernanz Angulo \\ Investigadora, Doctora en Filología Hispánica por la \\ Universidad Complutense de Madrid
}

Fecha de recepción: 30 de octubre de 2012

Fecha de revisión: 14 de enero de 2013

Para citar este artículo: De-Marchis, G. P. y Hernanz Angulo, B. (2013):

Modelo de relaciones retóricas para la integración de la imagen y el texto, Icono 14, volumen 11 (1), pp. 27-44. doi: 10.7195/ri14.v11i1.541 


\section{Resumen}

Hoy en día, el mensaje lingüístico está presente en casi todas las imágenes. Por ello resulta interesante abordar las cuestiones de integración verbo-visual. A lo largo de este artículo, tras una revisión de los modelos existentes, se ha ensayado una propuesta para el análisis de la integración verbo-visual. En esta integración, suele haber al menos dos operaciones, que consideramos como principales, a saber, la coherencia o sintonía, y el cambio de cantidad, que se divide en anclaje y fluctuación. Hemos enumerado otras cinco operaciones como secundarias: transformación, transfunción, inversión, traslocación, transtemporalidad. Estudios futuros deberán verificar si existen otras operaciones que es necesario añadir a este conjunto. Para ejemplificar el modelo se ha usado una obra artística, el cortometraje experimental "Pupila al viento" de Enrico Gras y Danilo Trelles (1949) con texto de Rafael Alberti.

\section{Palabras clave}

Verbo-visual - retórica - texto-imagen - multimodalidad - poesía visual - videoarte Pupila al viento - retórica visual

\section{Abstract}

Today, the linguistic message is present in almost all images. Therefore, it is interesting to address the issue of verbal-visual integration. Throughout of this article, following a review of some existing models, we propose a new model for the analysis of verbal-visual integration. In this integration, usually appear at least two operations, which we consider major, namely the consistency or harmony, and quantity change, which is divided into anchor and drift. We have listed five other secondary operations, namely: transformation, transfunction, reversal, translocation, transtemporality. Future studies should see if there are other operations that need to be added to this set. for exemplify the model has been used an artistic, experimental short film "A Pupil in the Wind" by Enrico Gras and Danilo Trelles (1949) with text by Rafael Alberti. 


\section{Key Words}

Word-visual - rhetoric - text-image - multimodality - visual poetry - video art - A

Pupil in the Wind - visual rethoric

\section{Introducción}

La imagen y el texto se han integrado desde la antigüedad. Pero es a partir del nacimiento del cine cuando esta integración ha tenido un crecimiento exponencial en cuanto a cantidad de producción. Hoy en día cada minuto se suben a YouTube miles de horas de grabaciones audiovisuales, gracias, especialmente, a la accesibilidad y el bajo coste de los sistemas digitales. En muchas de estas grabaciones existe la edición de la palabra y de la imagen, en un proceso consciente de integración. Ya señalaba Barthes(1986: 35) que hoy en día el mensaje lingüístico está presente en todas las imágenes: en la publicidad, en los artículos de prensa, ya sea en forma de titular o de texto explicativo, también en los comics, y hasta en el arte. Por todo ello un estudio sobre la integración de la imagen y el texto tiene hoy mayor relevancia que nunca.

El punto de partida del presente estudio es la observación de Barthes(1982: 75) que afirma que el punto débil de las clasificaciones del ornato (i.e. figuras y tropos) es que no tenemos reglas para inducir desde el producto artístico la figura que está 'escondida' detrás. Por ejemplo, para pasar desde 'se fue de rositas' a definir esta expresión como "metáfora lexicalizada" es necesario saber qué es una metáfora lexicalizada.

En este artículo quisiéramos aportar un pequeño avance en la comprensión de la retórica del discurso, como aquella disciplina que estudia el orden de relaciones y de transformaciones (Cohen, 1982: 42), y más concretamente nos interesa la integración de la imagen con la palabra. Para ello en estas páginas proponemos un primer modelo de clasificación para analizar, de forma inductiva y práctica, las diferentes operaciones verbo-visuales con el fin de comprender mejor las estructuras de los discursos y los metalenguajes usados. Para explicar mejor este prototipo, lo ejemplificaremos con una obra artística relevante, como es "Pupila al viento". Se trata de un análisis estructural que pretende comprender las relaciones entre elementos, y no sólo describirlos. 


\section{Clasificaciones retóricas y creativas}

El punto de partida de este estudio son cuatro modelos, que se sintetizan en un quinto, que es el que proponemos. Los modelos de partida son la clasificación de las figuras retóricas de Quintiliano; la clasificación de las relaciones texto-imagen de Barthes; la clasificación de las relaciones según la dicotomía identidad y oposición de Kergerant; y la llamada lista de control de 0sborn, que resume las operaciones de creación.

\section{Clasificación de Quintiliano}

La retórica ha estado desde siempre interesada en las clasificaciones (Barthes, 1982: 40). La razón es que la retórica intenta ordenar de una forma científica el discurso para que sea más eficaz. Es por ello un buen punto de partida para intentar estudiar la integración de las artes. Posiblemente, la clasificación más conocida de las figuras retóricas sea la de Quintiliano (1999), que las divide en cuatro categorías adición (adiectio), supresión (detractio), variación de orden (transmutatio) y sustitución (inmutatio). Esta clasificación es interesante por ser sencilla y eficaz a la hora de catalogar. Por ello, parece útil tenerla en cuenta a la hora de estudiar la retórica del discurso.

Las dos categorías básicas son la adición y la supresión, que son paralelas a las operaciones matemáticas de suma y resta. A partir de éstas se generan la sustitución, como supresión seguida de adición; y la variación de orden o transmutatio, como dos sustituciones recíprocas. Aunque este modelo se use para un nivel de estudio diferente del nuestro (i.e. las figuras retóricas funcionan más a un nivel sintagmático que paradigmático), es una buena referencia por ser una clasificación sencilla, que permite ordenar todos los elementos y que, en la mayoría de los casos, permite catalogar las figuras sin tener que conocerlas (p.ej. un asíndeton y una elipse son supresión, y una metáfora es sustitución, y si se comprende la operación, no es necesario saber qué es una metáfora para saber que lo que está ocurriendo es una sustitución). Al mismo tiempo, un modelo como éste admite tanto un análisis de los tipos de operaciones realizadas en una obra, como favorece un avance de la ciencia al ayudar en la comprensión de las relaciones entre elementos, en este caso, las figuras.

ICONO14 | Año 2013 Volumen 11 № 01 | ISSN: 1697-8293 | DOI: ri14.v11i1.541 


\section{Clasificación de Barthes}

A partir de la separación entre mensaje literal y mensaje simbólico, o denotación y connotación, Barthes identifica dos funciones del mensaje lingüístico respecto al icónico, el anclaje y el relevo (Barthes, 1986 : 35). Para entender esta clasificación, hay que saber que para Barthes toda imagen es polisémica, esto es, tiene muchos significados, una cadena flotante de significados de los que cada espectador selecciona algunos. Esto es aún más verdad en el caso de una imagen publicitaria.

El tomate del anuncio de Panzani analizado por Barthes, es un tomate (i.e. denotación) pero en ese anuncio es más importante su connotación, lo simbólico (i.e. su italianidad). Mas esta connotación no sería posible sin la denotación. La connotación dice (Barthes, 1986: 46) es paradigma, o sea, sistema, mientras que la denotación es sintagma, es decir, no es un sistema en sí mismo. Los connotadores, que son discontinuos (p.ej. el tomate y otra verdura presentes en el anuncio) se ligan entre sí a través de la denotación: los símbolos se integran a través de las denotaciones que forman la imagen.

La polisemia de la imagen provoca una incertidumbre que no resulta agradable al ser humano, que intenta fijar, anclar, la cadena flotante de significados. La palabra ayuda a fijar los elementos, a menudo refuerza a denotar. Se puede decir que las imágenes artísticas incluyen también una alta carga retórica, aunque en este caso, a menudo el texto quiera crear mayor ambigüedad, en vez de reducirla.

La otra función, el relevo, se crea entre texto e imagen como una función complementaria, que permite hacer avanzar una historia, y que sin embargo es coherente con ella. La palabra ofrece sentidos que no aparecen en la imagen, no trata simplemente de explicar la imagen, ni mucho menos, sino que toma el relevo de la imagen para que la historia vaya hacia su resolución. Se trata de una relación común en las narraciones, como el cine. La imagen y la palabra pueden no tener correspondencia, y por ello puede no haber integración verbo-visual, aunque la falta de integración es también una categoría de integración. Sucede por ejemplo cuando en una película hay un diálogo contado en plano y contra-plano. En ese momento el diálogo sirve para que la acción avance, y no para que imagen y sonido se integren y produzcan ningún tipo de operación. En la imagen fija, dice (Barthes, 1986: 37), la función de relevo es más escasa, centrándose en mayor grado en el cómic y en el humor gráfico.

DOI: ri14.v11i1.541 | ISSN: 1697-8293 | Año 2013 Volumen 11 Nº1 | ICONO14 
La clasificación de Barthes aporta la idea de la estrecha relación entre denotación y connotación. También aporta la idea de anclaje, como desambiguación de la imagen gracias al texto, y de relevo, que es una falta de relación propiamente dicha entre texto e imagen y que sin embargo permite a la narración avanzar. Sin embargo, nosotros nos centramos en las relaciones de cambio entre la imagen y el texto, algo que, propiamente no ocurren en el relevo.

\section{Clasificación de Kergétant}

D. Kergétant - citado en Durand, (1972: 85) y cuya fuente es Grolier (1962) - señala dos relaciones básicas en la naturaleza que une los elementos en cuanto a los significados: la similitud y la disimilitud. A su vez, en cada categoría hay dos grados, uno débil y uno fuerte. Así, para la similitud el grado fuerte sería la identidad, y el débil, la analogía. Por su parte, en la disimilitud encontraríamos como grado débil la diferencia, y como fuerte, la oposición. De esta manera se establece una gradación que va desde la identidad hasta la oposición. Esta idea es interesante porque el texto y la imagen tendrán una relación más o menos fuerte de similitud o disimilitud.

Durand posteriormente desarrolla este modelo poniendo en relación la idea de similitud/diferencia y solidaridad/oposición con una clasificación psicoanalítica de los opuestos/otros/mismos. Sin embargo, el psicoanálisis no parece aportar un criterio válido para este tipo de clasificaciones, y para entender su inclusión en la clasificación de Durand hay que tener en cuenta el contexto de los años 70 en el que el autor escribía.

Durand también aporta la división simple de forma y contenido. Así, se puede analizar la integración verbo-visual en su similitud-disimilitud, tanto en la forma como en el contenido, el significante y el significado. Una textura de la imagen puede ser un cambio en la forma; una repetición de una imagen es un cambio en la forma que puede influir en el contenido. Poner la imagen de una paloma al hablar de la paz o de la guerra, es un cambio en el contenido.

\section{Lista de control de Osborn}

Osborn es el creador del método creativo conocido como brainstorming o "lluvia o tormenta de ideas". Dentro del propio método, Osborn (2003) sugiere una técnica para mejorar las ideas generadas, se trata de un listado de control. Así, se somete la 
idea a una serie de operaciones que cubren las diferentes posibilidades creativas. Realmente, se trata de una clasificación de las operaciones de crear, como afirma García-Henche (1992), y consecuentemente, parece una manera apropiada y comprensiva para clasificar la integración entre texto e imagen, siempre que éstas se integren a través de un proceso creativo que produzca un cambio. En los años 70 Bob Eberle (Michalko, 2001) ordenó la lista de control a través de un acróstico, scamper. Así, 's' es sustituir, 'c' combinar, 'a' adaptar, $m$ ' modificar/magnificar, ' $p$ ' (i.e. put to other uses) cambiar de uso, ' $e$ ' eliminar/reducir, ' $r$ ' reordenar/invertir.

Esta clasificación de las operaciones creativas es suficientemente flexible como para englobar la mayoría las anteriores que hemos visto. Por ejemplo, una adición es sumar elementos, esto es, combinarlos; el anclaje es una forma de reducción; la analogía es una sustitución; una oposición se puede considerar como una inversión. El 'relevo' no se puede integrar en este modelo, sin embargo, el relevo, como hemos dicho, realmente es una operación de no-integración.

\section{Metodología}

Hasta ahora se han presentado cuatro clasificaciones. A partir de ellas hemos desarrollado un nuevo modelo, que se presenta en el apartado siguiente, "Propuesta de operaciones de integración verbo-visual". Tras generar el modelo de análisis de la integración verbo-visual, se ha elegido una obra artística relevante, y se la ha usado para ejemplificar el modelo propuesto. No es intención de este estudio ni cuantificar el uso de las diferentes operaciones en una obra artística, ni aplicar el análisis a un corpus de trabajos para validar el modelo. La intención de este artículo es presentar el modelo y tratar de explicarlo a través de ejemplos escogidos de una obra audiovisual. Por ello, esta propuesta no se puede generalizar como válida hasta que se aplique a un corpus de trabajos audiovisuales.

Antes de explicar el modelo, vamos a listar algunos supuestos y criterios que hemos usado en la creación de este modelo y en su aplicación.

A saber, los términos de una estructura tienen que ser solidarios, y si uno cambia, afecta al resto (Barthes, 1986: 34). Una obra es una estructura coherente, al igual que la personalidad. Una personalidad desestructurada es considerada enferma, y lo mismo puede decirse de una obra de arte que no tiene coherencia interna. 
Evidentemente, existen y tienen su espacio, pero las obras desestructuradas no se pretenden incluir en este modelo.

Otro supuesto, y que deriva del anterior, es que las integraciones verbo-visuales están especialmente relacionadas con el cambio: la imagen cambia algo del texto, 0 viceversa.

Además, suponemos que, en una obra audiovisual, generalmente el texto es anterior a la imagen. No ocurre lo mismo con la fotografía, pero en la creación audiovisual suele existir un texto anterior a las imágenes. Por ejemplo, en el cine, se escribe un guión previo al rodaje de la película; en la publicidad, existe una idea creativa previa a la generación de la imagen; en la preparación de una conferencia con elementos audiovisuales, o en un cómic, también suele haber un texto previo. La importancia de este supuesto estriba en que durante el proceso de análisis consideramos que las imágenes son posteriores al texto. Aunque a menudo la integración verbo-visual se puede estudiar como tal, otras veces el proceso de producción tiene sus efectos, y no es lo mismo pensar en las transformaciones de la imagen sobre el texto, que del texto sobre la imagen. Por ello, a menos que tengamos una información que nos diga lo contrario, suponemos que el texto se habrá creado antes que las imágenes. La obra que se ha usado para ejemplificar las operaciones es el cortometraje experimental Pupila al viento dirigido en 1949 por Enrico Gras y Danilo Trelles. En el texto sonoro, Rafael Alberti y María Teresa León leen un poema del propio Alberti. Se la ha considerado como la obra maestra del cine experimental uruguayo. La película estuvo perdida hasta que se encontró un negativo en la Cinemateca de Praga. Rafael Alberti recogió el texto en su libro Poemas de Punta del Este de 1961 bajo el título: "Pupila al viento. Palabras sincrónicas para un film, de Enrico Gras sobre Punta del Este" (Alberti, 1979: 43-53). De forma paradójica, el cortometraje que tomamos como ejemplo, es una excepción al supuesto de que el texto es anterior a la imagen, y Gras y Trelles rodaron las imágenes a modo de documental antes de que Rafael Alberti, mirando las imágenes en la moviola, escribiera el poema que las acompaña (Utrera, 1987).

Finalmente, el estudio de las operaciones de integración puede analizar varias dimensiones: lo sincrónico y lo diacrónico, la forma y el fondo. En la búsqueda de los ejemplos, y siempre que se ha podido, hemos tenido una perspectiva de análisis sincrónico, en el sentido que se han estudiado las relaciones entre imagen y texto en un momento, más que su evolución a lo largo del cortometraje. Los planos se

ICONO14 | Año 2013 Volumen 11 № 01 | ISSN: 1697-8293 | DOI: ri14.v1 1i1.541 
han usado como unidad. Además, no hemos hecho una diferenciación entre forma y fondo.

\section{Propuesta de operaciones de integración verbo-visual}

El modelo de clasificación que proponemos integra las clasificaciones vistas anteriormente (Tabla 1). Este modelo tiene dos operaciones primarias, y cinco secundarias. Entendemos "operaciones" como relaciones transformativas, mecanismos a través de los cuales la integración de dos conjuntos provoca unos cambios: la influencia mutua hace que el resultado de la intersección de imagen y palabra sea diferente que las partes por separado.

\section{Comparativa de las clasificaciones analizadas y operaciones verbo-visuales}

\begin{tabular}{|l|l|l|l|l|}
\hline $\begin{array}{l}\text { Clasificación } \\
\text { de Quintiliano }\end{array}$ & $\begin{array}{l}\text { Clasificación } \\
\text { de Barthes }\end{array}$ & $\begin{array}{l}\text { Clasificación } \\
\text { de Kergérant }\end{array}$ & $\begin{array}{l}\text { Lista de } \\
\text { control de 0s- } \\
\text { born/Scamper }\end{array}$ & $\begin{array}{l}\text { Operaciones de integración } \\
\text { verbo- visual }\end{array}$ \\
\hline $\begin{array}{l}\text { Adición } \\
\text { (adiectio) }\end{array}$ & Anclaje & Identidad & Combinar & $\begin{array}{l}\text { Coherencia o } \\
\text { Sintonía }\end{array}$ \\
\hline $\begin{array}{l}\text { Supresión } \\
\text { (detractio) }\end{array}$ & Relevo & Diferencia & $\begin{array}{l}\text { Reducir / } \\
\text { Eliminar }\end{array}$ & $\begin{array}{l}\text { Cambio de cantidad: Anclaje o } \\
\text { cambio a menos. Fluctuación } \\
\text { aumentativa cambio a más }\end{array}$ \\
\hline $\begin{array}{l}\text { Sustitución } \\
\text { (inmutatio) }\end{array}$ & Denotación & Analogía & Sustituir & $\begin{array}{l}\text { Transformación o cambio en la } \\
\text { forma }\end{array}$ \\
\hline $\begin{array}{l}\text { Variación de } \\
\text { orden } \\
\text { (transmutatio) }\end{array}$ & Connotación & Oposición & $\begin{array}{l}\text { Reordenar / } \\
\text { Invertir }\end{array}$ & $\begin{array}{l}\text { Inversión, cambio de dirección } \\
\text { o de orden }\end{array}$ \\
\hline & & & Adaptar & $\begin{array}{l}\text { Transfunción o cambio en la } \\
\text { función }\end{array}$ \\
\hline & & & Cambio de uso & $\begin{array}{l}\text { Traslocación o cambio en el } \\
\text { espacio o lugar }\end{array}$ \\
\hline & & $\begin{array}{l}\text { Modificar / } \\
\text { Magnificar }\end{array}$ & $\begin{array}{l}\text { Trastemporalidad o cambio en } \\
\text { el tiempo }\end{array}$ \\
\hline
\end{tabular}

Tabla 1

DOI: ri14.v11i1.541 | ISSN: 1697-8293 | Año 2013 Volumen 11 Nº1 | ICONO14 
Las operaciones principales son dos: la primera, la coherencia o sintonía, y la segunda, el cambio de cantidad; esta operación puede efectuarse tanto en cambio de significados o de elementos. Así, el anclaje y la fluctuación, o las repeticiones son cambios de cantidad, siendo la fluctuación, lo opuesto al anclaje.

Las cinco operaciones secundarias son: la transformación o cambio de forma; la transfuncióno cambio de función; la inversióno cambio de dirección; traslocacióncambio de lugar; y transtemporalidad o cambio de tiempo. La principal diferencia entre las operaciones principales y las secundarias es que las primeras aparecen siempre que hay una relación transformativa, en cambio las otras pueden aparecer o no. Además, cada operación puede referirse a la forma o al contenido, un tema que no tocamos en este estudio.

\section{Análisis y Resultados}

\subsection{Las operacionesde integración verbo-visual}

A continuación se explican y ejemplifican las siete operaciones propuestas.

\subsubsection{Coherencia o sintonía}

La operación principal, "coherencia o sintonía", supone que la imagen y la palabra van en la misma dirección, juegan juntas, tienen coherencia, o, si no tienen sintonía, se contradicen. Por ejemplo, es coherente una imagen de un elefante si el texto habla de la sabana, pero no lo es si el texto habla de la ciudad.

Esta operación suele ser de coherencia a lo largo de toda Pupila al viento (Gras y Trelles, 1949). Probablemente sea el resultado del propio método usado por Alberti para crear el texto a partir de la imagen. $Y$ aunque el texto y la imagen no llegan a la identificación, el texto suele acompañar a las imágenes. Por ejemplo, en el primer plano, se ve la lámpara del faro que gira y se oye el texto "pupila al viento, sola, en la noche, en el día" (Gras y Trelles, 1949) (Gráfico 1). Éste es un ejemplo de sintonía porque hay algo de coherencia entre la lámpara del faro y la pupila de un ojo, en sus movimientos constantes, en su visión elevada, en su forma. También es coherente el texto con la repetición diaria y nocturna de los giros que se ven en la imagen. En los planos siguientes, la imagen y el texto también tienen sintonía: 
mientras se ven unos engranajes mecánicos y el brazo del farero, se oye "te acompaña una mano solitaria" (Gras y Trelles, 1949) (Gráfico 2)

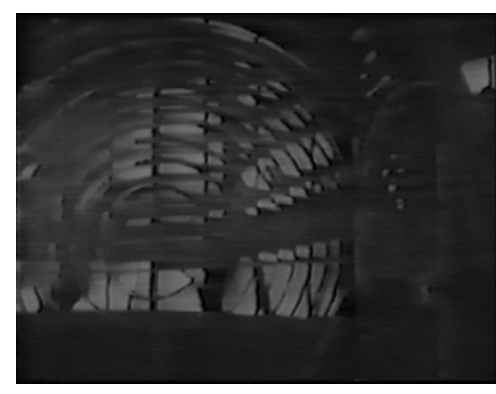

Gráfico 1: "Pupila al viento" Fuente: Gras y Trelles, 1949

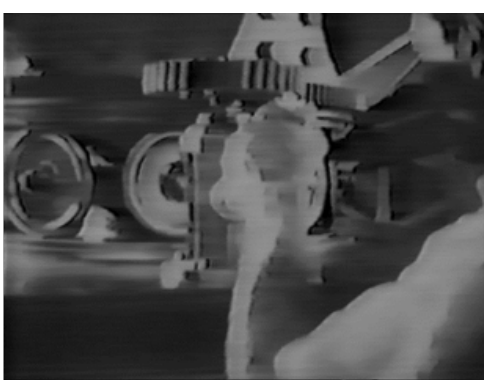

Gráfico 2: "Te acompaña una mano solitaria" Fuente: Gras y Trelles, 1949

\section{Cambio de cantidad}

La otra operación principal, el cambio de cantidad, consiste en aumentar o disminuir el número de significados, de connotaciones o de elementos, o subrayar algo, por ejemplo, a través de las repeticiones, aumentar o disminuir algo. Es decir, si se ve una abeja, y el texto dice "las abejas".

En Pupila al viento se utiliza a menudo la operación incluida en el cambio de cantidad, que hemos denominado de fluctuación aumentativa, que consiste en ampliar en número de significados o elementos a los pre-existentes. Resultan particularmente claros y frecuentes los casos en los que una palabra agrega significados a la imagen. En el mismo plano que se ha comentado antes (Gráfico 1), se ve la lámpara del faro girando sobre sí misma. La voz fuera de campodice: "gira al viento, sola, en la noche, en el día" (Gras y Trelles, 1949). En este caso tenemos una operación de coherencia, y tenemos también un cambio de cantidad de suma de elementos. La interacción entre imagen y verbo no cambia los significados de lo que se ve, sino que se ha añadido los elementos "soledad", "día y noche", pero la bombilla sigue siendo la misma.

En el plano 25 se ve a un grupo de lobos marinos moviéndose e interaccionando entre sí en la playa, mientras el texto dice "Y los lobos son niños, / juguetones, risueños" (Gras y Trelles, 1949) (Gráfico 3). Los lobos marinos ya no son animales que se relacionan entre sí, sino que son niños que juegan. Se ha abierto el campo de significados de la imagen gracias a la interacción con la palabra. 


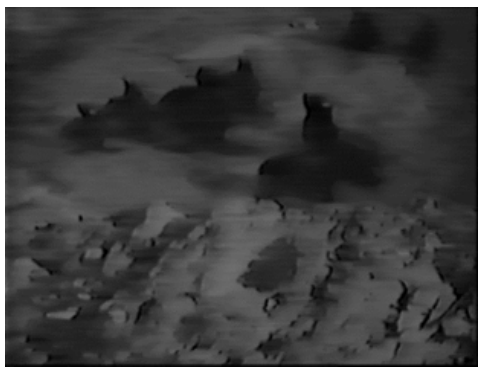

Gráfico 3: "Los lobos son niños" Fuente: Gras y Trelles, 1949

La gran frecuencia con el que aparece la operación de fluctuación aumentativa, en Pupila al viento posiblemente sea debido al procedimiento creativo usado. Como hemos señalado, Alberti ha escrito el poema sobre la imagen terminada. Un poeta mediocre se hubiera limitado a describir las imágenes con el texto poético y la palabra, sin aportar nada. De esta manera el texto se hubiera convertido en un parásito (Barthes, 1986). Alberti, aún cuando describe las imágenes de un plano, siempre añade valores y/o provoca transformaciones. Por ejemplo, en el plano 24 se ve una cometa volando cerca del faro; el texto dice: "el aire es una cometa / en la mano de un niño" (Gras y Trelles, 1949) (Gráfico 4). Ya sabemos que la cometa está en la mano de un niño, porque lo hemos visto, lo que se nos añade a la imagen, y que nos amplía su significación, es la comparación con el aire. Aquí, además de una operación de coherencia, y de fluctuación aumentativa, como cambio de cantidad de significados, también tenemos un cambio de forma, que estudiaremos más tarde.

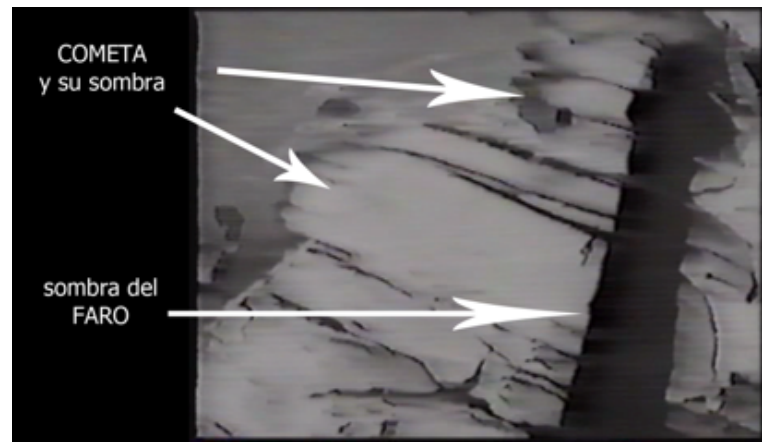

Gráfico 4: "El aire es una cometa" (texto y flechas son añadidos de los autores) Fuente: Gras y Trelles, 1949 


\section{Transfunción o cambio en la función}

La transfunción consiste en que, a través del efecto de la palabra sobre la imagen, o lo inverso, un elemento cambia de función. Por ejemplo, si se viera la imagen de un bolígrafo y el texto le llamara "puñal".

Vemos un ejemplo de cambio de función en el plano 40; en la imagen se ve un pozo con el cubo atado a una cuerda y oscilando; al fondo está el faro. El cubo se balancea por el viento de un temporal y el texto dice de forma rítmica: “ $i$ Tin! ¡Ton!/ ¡Tin! ¡Tan! / ¡Tin! ¡Ton! / ¡Tin! ¡Tan!” (Gras y Trelles, 1949) (Gráfico 5). El cubo movido por el viento ha cambiado su función por el de badajo de una campana. La existencia de una operación no impide que haya otras. En este caso, se puede hablar no sólo de un cambio de función, sino también de forma, porque un badajo y un cubo no tienen una misma apariencia.

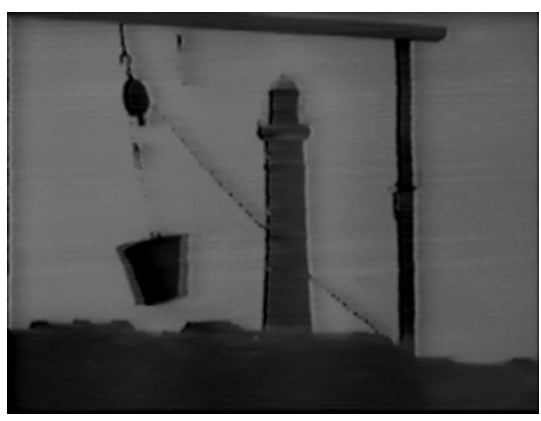

Gráfico 5: “iTin! ¡Ton!/ „Tin! ¡Tan!” Fuente: Gras y Trelles, 1949

\section{Transformación o cambio en la forma}

La transformación es el cambio de una forma a otra por la integración de elementos visuales y textuales. Por ejemplo, si se ve la imagen de un cubo y se dice "triángulo". En este caso, la imagen y el texto no serían coherentes.

En Pupila al viento, en el plano 106, se ve una sombrilla sola y cerrada, cerca de la orilla del mar; el texto dice: “Qué tallo y de qué flor/ ha crecido en la arena?" (Gras y Trelles, 1949) (Gráfico 6).

Tenemos una operación de cantidad, al aumentar el número de significados de las sombrillas hacia las flores. La sombrilla cerrada cerca de las olas es también algo más: el palo es un tallo, y en su conjunto es una flor cerrada, que después se abrirá. Ha habido una operación de transformación. 


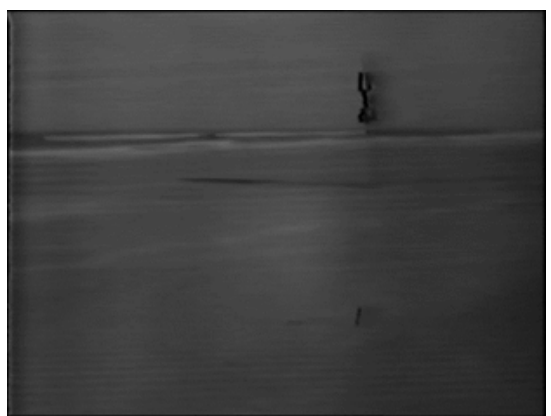

Gráfico 6: “¿Qué tallo y de qué flor/ ha crecido en la arena?" Fuente: Gras y Trelles, 1949

En el plano 25, comienza con un grupo de lobos marinos moviéndose e interaccionando entre sí en la playa, mientras el texto dice que "los lobos son niños, / juguetones, risueños" (Gras y Trelles, 1949) (Gráfico 7). Ya no son animales, sino que se transforman en niños que se divierten. Se ha abierto el campo de significados de la imagen, gracias a la interacción con la palabra, pero también hay una operación de cambio de forma.

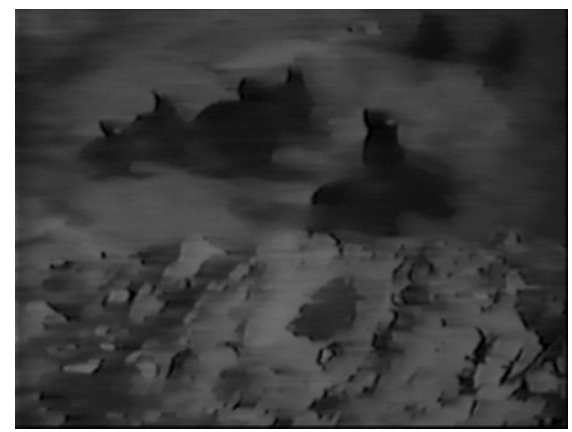

Gráfico 7: "Los lobos son niños" Fuente: Gras y Trelles, 1949

En estos ejemplos que se han mencionado, las dos operaciones son también un cambio en la cantidad: las operaciones de transfunción y transformación suelen ser también unos procedimientos de cambio de número, generalmente de significados.

\section{Inversión, cambio de dirección o de orden}

Esta operación consiste en una relación en la que hay algún tipo de desorden o cambio de orientación. Un ejemplo podría ser si en el plano se ve en la derecha una caracola, y el texto dijera "allí está, a la izquierda". En muchos otros casos esta operación puede ser diacrónica. 


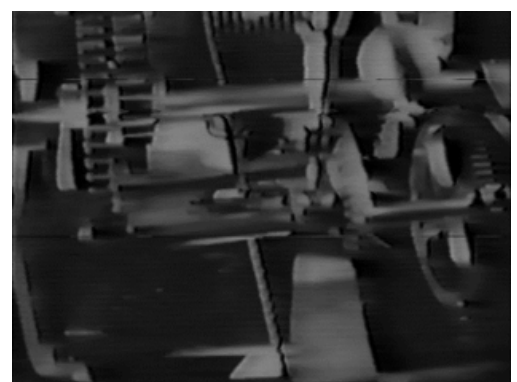

Gráfico 8: "Gira sola, gira" Fuente: Gras y Trelles, 1949

En el plano 4 se oye "Gira sola, /gira./Gira sola,/gira..." (Gras y Trelles, 1949) (Gráfico 8) mientras se ve los engranajes que giran. Aquí ha habido un cambio de orden porque el texto se refiere a la imagen primera, la lámpara que gira, la pupila, mientras se ven los engranajes. Al mismo tiempo, la imagen es coherente y hay una operación de fluctuación aumentativa, puesto que se puede entender que el texto amplía el sentido de la imagen, y que los engranajes son parte de una unidad mayor, que es la lámpara que gira.

\section{Traslocación o cambios en el espacio}

Un cambio en el espacio, o traslocación, se puede dar cuando la imagen presenta un espacio, mientras el texto hace referencia a otro. Por ejemplo, si en un plano se observa a una persona durmiendo, y se habla de la luna.

En Pupila al viento, se presentan unas imágenes de un barco metido en una botella, y se relata un temporal. El barco en la botella se mueve como si estuviera en la tempestad, y la voz fuera de campo grita “;socorroooo!” (Gras y Trelles, 1949) (Gráfico 9), como si los marineros, estando en la mar en borrasca, pidieran auxilio.

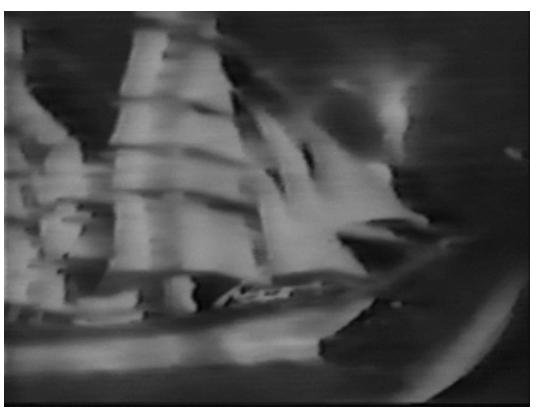

Gráfico 9: “isocorroooo!" Fuente: Gras y Trelles, 1949 
Más adelante, se ve una sombra proyectada sobre una playa en la que, en la parte superior aparecen varias estrellas marinas, más oscuras. De repente el plano se transforma en negativo, y la claridad de la arena se vuelve negra, mientras la oscuridad de las estrellas marinas se vuelve clara, como si fueran estrellas en el cielo nocturno. Aquí ha habido una operación de cambio de espacio o traslocación, (i.e. de la arena al cielo) y también de cambio de tiempo o transtemporalidad (i.e. del día a la noche).

\section{Transtemporalidad o cambios de tiempo}

Al igual que el cambio de espacio, la transtemporalidad implica algún tipo de cambio temporal. Un ejemplo sencillo podría ser una imagen en la que se suceden las estaciones del año, y la voz que afirma: "pasan los años".

En Pupila al viento, se ven las imágenes de un pecio en la arena, sólo la estructura, como un esqueleto, y se oye la voz del capitán que dice “ ¡Búscame entre las costillas/ de este gigante del mar! / ¡Soy el capitán del viento! ¡Soy el capitán! (Adiós capitán)" (Gras y Trelles, 1949) (Gráfico 10). En la operación, el tiempo del pasado, la voz del capitán, se manifiesta en el presente a través de las imágenes.

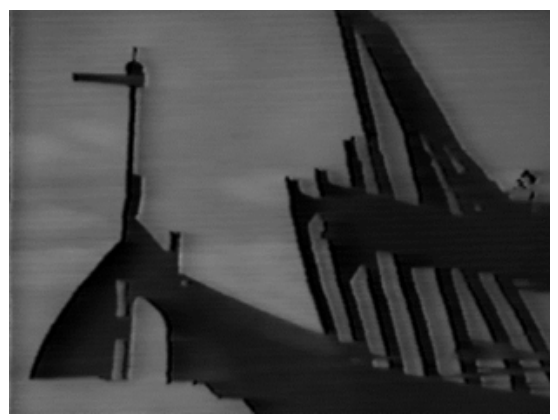

Gráfico 10: “;Soy el capitán!” Fuente: Gras y Trelles, 1949

En el plano 10, se muestra un ovillo que, tras rodar por unas escaleras, llega hasta una puerta. Cerca está una mecedora, y al fondo, dos niños que juegan. El texto dice "el reloj del tiempo / nace y muere aquí" (Gras y Trelles, 1949). Se apela así a un tipo de cambio de tiempo, en el que se representa a la juventud y a la vejez (i.e. a través de la mecedora). 


\section{Discusión}

A lo largo de estas páginas, tras una revisión de los modelos existentes, hemos presentado una propuesta para el análisis de la integración verbo-visual. Luego hemos buscado ejemplos de las diferentes categorías en una obra artística para hacer más comprensible el modelo.

Cuando texto e imagen se integran en una unidad, puede haber muchas operaciones, y de hecho es común que en el lenguaje artístico, el texto y la imagen se integren con muchas operaciones. Pero suele haber al menos dos, la operación de coherencia y la de cambio de cantidad. Por ello, consideramos estas operaciones como las principales. Hemos enumerado otras cinco como secundarias.

Este tipo de análisis nos ofrece un punto de vista nuevo a la hora de estudiar los resultados de la integración de la imagen con el texto. El estudio de los diferentes elementos por separado es necesario e intuitivamente previo al de las operaciones de integración. Sin embargo se requiere el análisis y sistematización de la suma de las partes. De este estudio obtenemos información útil sobre el texto como sistema.

No en todos los casos el texto encaja tan bien con la imagen, debido, como hemos comentado, al proceso de creación seguido y que no es demasiado común.

Aunque no hayamos hecho un estudio cuantitativo de las operaciones presentes en la obra usada para ejemplificar el modelo, se puede intuir que en esta obra hay, por lo general, coherencia y cambio de número hacia el aumento, creando polisemia, y juegos visuales y verbales. Desafortunadamente, Alberti nunca pudo realizar su deseo de rodar un cinepoema del todo propio, y ésta es su obra más cercana al cine que él tanto amaba.

Estudios futuros deberán validar el modelo a través de su aplicación a un amplio corpus de análisis, y cuantificar los resultados. Esos mismos estudios podrán verificar si existen otras operaciones que es necesario añadir a este conjunto. 
44 | Giorgio P. De Marchis y Beatriz Hernanz Angulo

\section{Referencias}

Alberti, R. (1979). Poemas de Punta del Este. Barcelona: Seix Barral.

Barthes, R. (1982). Investigaciones retóricas I. La antigua retórica. Barcelona: Ediciones Buenos Aires.

Barthes, R. (1986). Lo obvio y lo obtuso. Barcelona: Ediciones Paidós Ibérica. Cohen, J. (1982). Teoría de la figura Investigaciones retóricas II. Barcelona: Ediciones Buenos Aires.

García-Henche, F. G. (1992). Cuadro guía para operaciones creativas Operaciones creativas. Carpetas de recursos didácticos. Madrid: Servicios de publicaciones del MEC-Vicens Vives.

Gras, E., y Trelles, D. (Directores). (1949). Pupila al viento [cortometraje]. Uruguay.

Grolier, E. d. (1962). Étude sur les catégories générales aplicables aux classifications documentaires. UNESCO.

Michalko, M. (2001). Thinkertoys. Barcelon: Ediciones Gestión 2000.

Osborn, A. F. (2003). L'arte della creativity ( $7^{\text {a }}$ ed.). Milano: Franco Angeli.

Quintiliano, M. F. (1999). Sobre la formación del orador Obra completa. Libros VII-IX. Edic. bilingüe: Latín-Español (Vol. 3, pp. 30-100). Salamanca: Universidad Pontificia de Salamanca.

Utrera, R. (1987). Literatura cinematográfica, cinematografía literaria. Sevilla: Ediciones Alfar.

ICONO14 | Año 2013 Volumen 11 Nº1 | ISSN: 1697-8293 | DOI: ri14.v1 1i1.541 